\title{
Is big data for big farming or for everyone? Perceptions in the Australian grains industry
}

\author{
Aysha Fleming ${ }^{1}$ (D) $\cdot$ Emma Jakku $^{2} \cdot$ Lilly Lim-Camacho ${ }^{3} \cdot$ Bruce Taylor $^{2} \cdot$ Peter Thorburn $^{4}$
}

Accepted: 23 March 2018 / Published online: 17 April 2018

(C) The Author(s) 2018

\begin{abstract}
Continued population growth and land intensification put increasing pressure on agricultural production and point to a need for a 'step change' in agriculture to meet the demand. Advances in digital technology — often encapsulated in the term 'big data' - are increasingly assumed to be the way this challenge will be met. For this to be achieved, it is necessary to understand the ways that farmers and other industry stakeholders perceive big data and how big data might change the industry. It is also necessary to address emerging moral and ethical questions about access, cost, scale and support, which will determine whether farms will be able to be 'big data enabled'. We conducted a discourse analysis of 26 interviews with stakeholders in the grains industry in Australia. Two main discourses were identified: (1) big data as a technology that will significantly benefit a few larger farms or businesses - Big Data is for Big Farming — and conversely (2) big data as a way for every farmer to benefit — Big Data is for Everyone. We relate these findings and the literature on adoption of technology and social studies in agriculture to the potential of farmers to embrace big data, from basic concerns about network infrastructure through to more complex issues of data collection and storage. The study highlights that there are key questions and issues that need to be addressed in further development of digital technology and big data in agriculture, specifically around trust, equity, distribution of benefits and access. This is the first study of big data in agriculture that takes a discourse analysis approach and thus interrogates the status quo and the prevailing norms and values driving decisions with impacts on both farmers and wider society.
\end{abstract}

Keywords Digital technology $\cdot$ Agriculture $\cdot$ Discourse analysis $\cdot$ Farmer views $\cdot$ Values $\cdot$ Risks

\section{Introduction}

Big data and its potential to 'revolutionise' the industry (Huberty 2015) are of interest to agricultural industries and researchers across Australia, and globally. According to Wolfert et al. (2017), 'a unifying definition of big data is difficult to give, but generally it is a term for data sets that are so large or complex that traditional data processing applications are inadequate'. The capability to extract information

Aysha Fleming

Aysha.Fleming@csiro.au

1 CSIRO, Land and Water, Hobart, Tasmania 7000, Australia

2 CSIRO, Land and Water, Dutton Park, Brisbane, Queensland 4102, Australia

3 CSIRO Land and Water, Pullenvale, Brisbane, Queensland 4069, Australia

4 CSIRO, Agriculture and Food, St Lucia, Queensland 4067, Australia and insights at a larger scale than previously possible (Sonka 2015) may appear to benefit those upstream or downstream of the farm more than farmers themselves; however, farmers may also benefit directly from much more accurate, timely and context-specific information to inform their decision-making (see Fig. 1 for a visual representation). The new capabilities underpinning big data include cloud computing, social media, artificial intelligence, sensor technology, the Internet of Things, robotics, mobile applications and increased capacity for storing and analysing large data sets previously only possible using supercomputers (Kitchin 2014; Sonka 2015; Wolfert et al. 2017). In many cases, the technology for big data applications on farms already exists. For example, it is now possible to combine large data sets and analyses including:

- Long-range climate forecasts

- Crop production models

- Sensors on farms

- Local weather station data

- Pest management data 
- GIS mapping technology

- Industry historical data (past yields, market data)

- Current consumption data (supply chain logistics, prices, distributions, volumes)

- Social media data (trends, events, political and social movements)

(Kitchin 2014; Sonka 2015; Wolfert et al. 2017).

In practice, the concept of big data is as variable as the diversity of farmers (and farming styles) who might apply it (Vanclay et al. 1998; Howden and Vanclay 2000). For example, big data might be about increasing on-farm productivity (individual farmer benefits) or improving logistic and market analysis (industry benefits). Yet, while farmers may perceive and apply big data in a variety of different ways, those farming enterprises that have greater levels of value chain integration and higher quality information may benefit more, while
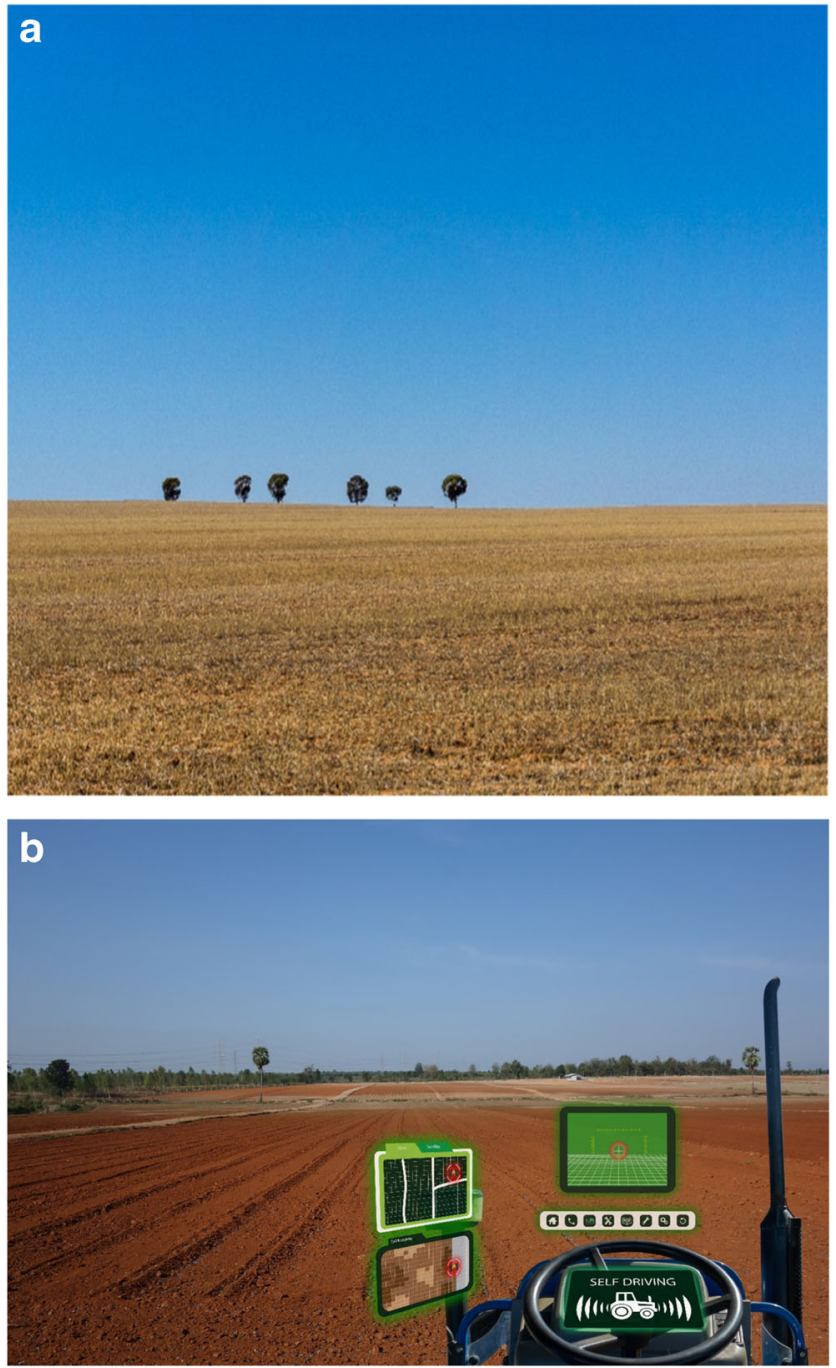

Fig. 1 a Wheat field after harvest in the Wimmera-Mallee region of Victoria, Australia. Photo by Emma Jakku. b Simulation of big data in practice. Adobe Stock Image ekkasit919 businesses with less access to information (because of less dense advice networks) who are less integrated into the value chain may be more exposed to risk (Jakku et al. 2016). Advances in digital agriculture are creating the opportunity to collect vast quantities of data which in turn open the possibility for big data approaches. There are already examples in Australia (e.g. Kirby Smart Farm, Queensland Digital Homestead, Sense-T, Digiscape), where these systems are being deployed to improve productivity and profitability and minimise risks within agriculture (Jakku et al. 2016). These examples include sensor information from tractors on multiple farms centrally collected and analysed in the cloud to refine current estimates of, and predict future volume, quality and/or price of products, as well as information about crop status, storage capacity and market variables to optimise logistics (Wolfert et al. 2017).

Despite these examples, there remain a number of challenges to 'rolling out' the use of big data across the farming sector. One of the largest of these challenges is the moral and ethical questions about access, cost, scale and support, which will determine whether it will ever be possible, or indeed desirable, for all farms to be 'big data enabled', or whether it is an inevitable progression of modernisation in agriculture (Carolan 2016b). Another key question in an Australian context is whether big data will help the industry overcome competition from new entrants to the market such as India and China, fluctuations in market demand, increasing niche market opportunities requiring different approaches, and a plateauing of the intensification of the industry (producing more from less by increasing efficiencies). The Australian grains industry is also facing some challenges in common with other agricultural crops in Australia and globally, including an ageing workforce, difficulty accessing skills and labour, increasing farm sizes, corporatisation and climate change (Robertson et al. 2016; Jakku et al. 2016). How big data will influence all of these issues is of huge import to the success of agricultural industries both in Australia and globally.

Big data applications might be assumed to be more readily suited to large farms and industries that already use data in their decision-making and have access to data capture from machinery, greater access to capital and resources and find larger-scale decision-making more relevant. However, there is little research examining this assumption. A number of reviews and reports have recently been released discussing the potential of big data for agriculture and highlighting the gaps in knowledge or inhibitors to more widespread uptake of the technology (Poppe et al. 2015, Keogh and Henry 2016, Jakku et al. 2016, Wolfert et al. 2017). The prominent gaps and inhibitors tend to be the social questions of equity and access, distribution of benefits, management and governance, issues of trust and reciprocity and rights and ownership. Discourse analysis - an examination of language and the implicit implications of language use-and its explicit focus on assumptions, values and the consequences 
thereof (who benefits) has not yet been employed as a methodology to address these questions and have a lot to offer for understanding the range of potentials for individual farmers to benefit from big data.

The objective of this paper is to examine language use and its effects, in order to critically reflect on the implications of big data in agriculture. We examine language use and its effects through discourse analysis and aim to raise questions about who benefits from big data and pose issues of access, equity and agency that need to be acknowledged in further development of digital technology. By opening up the values and assumptions in perceptions of big data and challenging the ultimate consequences that we are already on the path to, it becomes possible to alter the outcomes, if desired. This paper holds up a mirror to the discourses of big data that are currently circulating and poses the question: is this heading in the right direction? Or are there other issues that need to be actively brought in to the further development of big data in agriculture? The paper does not aim to answer these questions, but to make sure that these aspects are made visible, rather than normalised into the status quo of big data in agriculture without due consideration.

\subsection{Conceptual framework: discourse analysis as a tool to increase understanding of farmer adoption}

It is now well recognised that an individual farmer's engagement with new technology is not a simple technical matter (Vanclay 2004). Instead, adoption of technology involves active consideration of values, beliefs, identities, goals and social networks (Kuehne et al. 2017; Allen et al. 2017; Pannell et al. 2006; Stone and Hochman 2004; Vanclay 2004; Leeuwis 2004). Knowledge of this social context also requires knowledge of the institutions interacting with farmers and farm communities including technology designers and producers, industry bodies, brokers and marketers, supply chain partners and supermarkets and consumers (Carberry et al. 2002; Stone and Hochman 2004; Jakku and Thorburn 2010; van Meensel et al. 2012; Allen et al. 2017). Yet, such considerations are rare investments in the development and dissemination of the technologies themselves.

The increasing body of work on decision support systems and decision-making on farms demonstrates that the way an individual relates to new technology is mediated through different spheres of influence, from macro-ideologies, such as politics, religion or culture; meso-social constructs (for instance institutions, networks or communities); and micro-individual circumstances, influenced by identities, values and goals (Allen et al. 2017; Pannell et al. 2006; Stone and Hochman 2004; Vanclay 2004; Llewellyn and Ouzman 2014). A useful way to understand these macro, meso and micro spheres of influence is through discourse analysis (Foucault 1980; Jorgensen and Phillips 2002) because discourse analysis examines language as both the cause and the result of the social structures that shape the macro-, mesoand micro-systems we operate within. Thus far, the literature on adoption of big data in agriculture has not sufficiently examined language use and its links to social structures. Some discussions of the social constructions and the social consequences of big data come close, however (Carolan 2016a, 2016b; Carbonell 2016; Boyd and Crawford 2012).

Discourses are particular ways of using language in particular situations. Put simply, discourse analysis is an examination of language and the implicit implications of language use. Discourse analysis can be done in many ways, examining different aspects, such as syntax, punctuation or turn-taking. More often, discourse analysis examines issues of power and ideology (Jorgensen and Phillips 2002). The method we have chosen in this paper identifies key language, rules, norms, and values and assumptions.

- Key language - words that are used frequently, or in multiple ways, or laden with implicit value positions

- Rules - what is considered should or should not be done and what is right and wrong

- Norms - what is accepted as usual

- Values and assumptions - unconscious ideas and associations and what is valued and prioritised in decision-making

It is important to be aware of language and the implications of simple word choices, on framing and shaping ideas, and discourse analysis brings these to attention. Discourse analysis can reveal how seemingly simple and innocent language can actually have powerful effects on perceptions of good or bad, right or wrong or who is included and excluded, which would otherwise be normalised and invisible and thus unable to be challenged.

Discourses work toward normalisation and act in opposition to other competing discourses and therefore are dynamic and in a state of constant change (Wetherell et al. 2001). With an awareness of how a discourse is operating, it becomes possible to conceive how that discourse might be different, or to begin to reject it altogether (Darier 1999). Everything we do is within discourse, so discourses are influential social constructions that should be examined, particularly in relation to behaviour change. The study of discourse is a growing component of many academic fields, including environmental social science (Dryzek; 2006; Hajer and Versteeg 2005, Carvalho 2007; Bäckstrand and Lövbrand, 2016). It is less common within agriculture (Finan 2007; Fleming and Vanclay 2010; Johnston 2012). The concept of cultural scripts does have some overlap with discourse analysis because it looks at norms and farmers' meanings (Vanclay and Enticott, 2011), but even this slightly simpler version of discourse analysis is under-considered in agriculture, and so, the potential for studying discourses as a practical approach to 
facilitating behaviour change is yet to be realised. Discourse analysis challenges the fundamental framing of ideas which may otherwise lead to the continuation of the status quo and perpetuation of existing inequalities, issues which have held back agriculture in the past, especially in terms of adoption of new technologies which did not fully account for heterogeneous farmer styles, values, experiences, histories and needs. Discourse analysis is different from current approaches because it challenges the source of the problem of adoption (conflict in values, culture clashes, lack of trust, lack of participation), rather than the symptoms (lack of awareness, lack of information, lack of skills). Using discourse analysis, we can use language to examine the whole social system and make better progress in the 'problem' of adoption. Through discourse analysis, we have the ability to choose whether particular discourses are desirable or not and to plan whether to promote or resist those discourses. We can do this by encouraging the discourses that we choose, to try to cement the benefits and opportunities that the discourses present, or by working to change aspects of the discourses that are not desirable to avoid or limit the difficulties they foreshadow.

\section{Materials and methods}

\subsection{Interviews}

In 2016, we interviewed 26 grains industry stakeholders to explore their perceptions of, and experiences with, digital technologies and big data in agriculture. The stakeholders that we interviewed included 14 participants from the dryland broad acre and mixed farming systems regions of Wimmera and Mallee, Victoria, to provide regional-level grains sector insights, and 12 policy and institutional participants from the grains industry at the state and national levels (see Table 1 for details and Fig. 1 for an image to reflect the location).

These were sourced from a combination of referrals from industry experts and industry networks, attendance at industry events and conferences and Internet research.
Interviews were generally $1 \mathrm{~h}$ in duration and nine were conducted face-to-face in the Wimmera-Mallee region, while the remaining 17 interviews were conducted via telephone. Ethics clearance was granted (070/15).

Interview questions included:

- What does the supply chain look like for your business? For instance, who are the main players and how are they connected?

- How does information move between your business and others across the supply chain?

- From your perspective, how do you establish and maintain trust between your business and others you work with?

- When people talk about digital agriculture and big data, what does that mean to you?

- How much is big data part of your current business or future strategy?

- What benefits or opportunities do these digital technologies and big data applications provide?

- What problems or risks do they present?

- What do you think are the main challenges or changes in relation to digital agriculture and big data that are likely to impact on the grains industry in the next 5-10 years?

- What are the big trends you see coming up?

- Who do you think should be responsible for managing information or data flows along the supply chain, e.g. governments, corporates, farmer groups or farmers?

- What does this mean for current groups or businesses in the grains industry? Are there going to be winners and losers?

- What types of processes, rules or incentives might help to manage or reduce some of these risks (e.g. protocols, practices, partnerships, support etc.)?

\subsection{Analysis}

The interviews were digitally recorded and professionally transcribed. We used the qualitative data analysis software
Table 1 Interview participants by stakeholder category

\begin{tabular}{llll}
\hline \multirow{2}{*}{ Stakeholder category } & \multicolumn{2}{l}{ Number of interview participants } \\
\cline { 2 - 4 } & Wimmera-Mallee region & Policy and institutional level & All participants \\
\hline Input provider & 1 & 3 & 4 \\
Grower & 5 & 0 & 5 \\
Grower group & 4 & 4 & 8 \\
Research and consulting & 1 & 2 & 3 \\
Logistics and trading sector & 1 & 1 & 2 \\
Local government & 2 & 0 & 2 \\
State government & 0 & 2 & 2 \\
Totals & 14 & 12 & 26 \\
\hline
\end{tabular}


QSR NVivo® (QSR International, version 10) to aid the coding, analysis and management of the data. Interview data were categorised into a hierarchical structure of themes and sub-themes through multiple rounds of coding, informed by (and informing) our analytical framework. We followed constructivist interpretations of grounded theory (Charmaz, 2006; Fleming and Vanclay 2009; Glaser and Strauss 1967), which involves qualitative coding for key concepts and uses of language from the sentence level, grouped into categories and themes in order to reveal different connections and insights (Denzin and Lincoln, 2011). While the codes, categories and themes (see Table 2) could be organised in different ways, the main point of our analysis for this paper was the language used (see below). The coding hierarchy is a preliminary step in this case to understanding, sorting and representing the data.

The categories and themes were interrogated to see if they held up as discourses, looking for cross cutting ideas that were significant enough to have their own recognisable collective uses of key language, rules, norms and values and assumptions (Jorgensen and Phillips 2002; Fleming et al. 2014). We then compared key risks for the industry and how both discourses framed these risks. Further discussion of the consequences of the values and assumptions and differences in framing of risks in the discourses highlights the questions and issues that need to be acknowledged in further development of big data in agriculture.

\section{Results and discussion}

We have divided the results into two core discourses that emerged from the grounded theory analysis-Big Data is for Big Farming and Big Data is for Everyone. For more of a direct discussion of the results and practical implications (without the leap to discourse analysis), we refer readers to Jakku et al. (2016).

\subsection{Discourse: Big Data is for Big Farming}

The first discourse was around big data being more useful and more appropriate or generating more benefits to big farms or business connections - the industry brokers, marketers and corporations - by having access to more accurate, up to date industry wide information and by being better set up to implement big data applications. Big farms and big businesses were regarded as having a greater ability to cover upfront costs of implementing big data systems, having access to a larger store of existing data, a greater ability to source skills and advice in the application and interpretation of big data and more experience in setting up contracts to manage data, all of which are easier for bigger entities to manage.
Table 2 Coding hierarchy

\begin{tabular}{|c|c|}
\hline Theme & Codes \\
\hline $\begin{array}{l}\text { Big Data is for Big } \\
\text { Farming }\end{array}$ & $\begin{array}{l}\text { Australian farmers are tough } \\
\text { Avoid using the term big data } \\
\text { Changes to farming and rural communities } \\
\text { Changing markets } \\
\text { Cheaper inputs } \\
\text { Cost squeeze } \\
\text { GM and breeding } \\
\text { Increasing focus on digital agriculture } \\
\text { Info and data becomes more valuable } \\
\text { Use of UAVs and drones } \\
\text { Validating remote sensing models } \\
\text { Change in skills required to be successful farmer } \\
\text { Changes the nature of research and science } \\
\text { Efficiency } \\
\text { Farm machinery purchasing decisions } \\
\text { Farmers' pride in their on-farm records } \\
\text { Farming become more complex } \\
\text { Gap between top farmers and rest } \\
\text { Importance of farm management decisions } \\
\text { Improved computing power to find new insights } \\
\text { Linked to precision ag and yield mapping } \\
\text { Promoting start-ups and private sector innovation } \\
\text { Tech adoption stories } \\
\text { Technology part of every aspect of life now } \\
\text { Tool for efficient, effective ag } \\
\text { Unclear what the role for government might be } \\
\text { Uses of big data and digital ag }\end{array}$ \\
\hline $\begin{array}{l}\text { Big Data is for } \\
\text { Everyone }\end{array}$ & $\begin{array}{l}\text { Still requires human decision-making } \\
\text { Requires collaboration and collective action } \\
\text { Re-framed as farm-collected or farm-generated } \\
\text { data } \\
\text { Pride in the historical legacy of family farming } \\
\text { Positive perceptions of big data } \\
\text { Needs to fit with farmers intrinsic knowledge and } \\
\text { expectations } \\
\text { Many different ways to farm } \\
\text { Identity and decision-making } \\
\text { Governance policies } \\
\text { Governance recommendations } \\
\text { Responsibility } \\
\text { Safety measures } \\
\text { Support required } \\
\text { Different levels of use and understanding } \\
\text { of digital age } \\
\text { Description of supply chain dynamics } \\
\text { Benefits and opportunities } \\
\text { Aggregates and consolidates data for improved } \\
\text { decisions }\end{array}$ \\
\hline Risks identified & $\begin{array}{l}\text { Differences btw Aust and US or European } \\
\quad \text { context } \\
\text { Infrastructure } \\
\text { Negative perceptions of big data } \\
\text { Technical risks } \\
\text { Social and political risks } \\
\text { Not fully maximising current data } \\
\text { Limitations of short term projects } \\
\text { Financial risks } \\
\text { Technological lock-in } \\
\text { Trust } \\
\text { Uncertainty }\end{array}$ \\
\hline
\end{tabular}


Key language: industry gaps; industry divide; pushing boundaries; maximising profits; smart farming; efficiency. Rules: strive for maximum control, e.g. contractual arrangements. Norms: individualism; every farmer for themselves; maintain competitive advantage; revolution is an inevitable part of competition. Values and assumptions: economic values; bigger is better; survival of the fittest; farming is business; information is valuable.

\subsubsection{Key language: widening gap}

So this top $20 \%$ thing becomes more and more, because there's so many - there's less people in each percentage bracket, I suppose. So the gap between the farmers becomes just wider. So the gap between an average farmer and top farmer is increasing. (Grower group 5)

\subsubsection{Key language: smarter farming}

Big data and automation and all that kind of thing will absolutely drive up farm sizes, because growers will be able to do more with less time... if you have a look at the grains industry over the last however many decades, we've gone from 40,000 growers, producers to 24,000 , so that rationalisation is already happening. It's because of mechanisation and smarter farming practices. If it shrunk down to 15,000 farms in the next 10, 15 years, I would not be surprised. (Grower group 4)

\subsubsection{Key language: efficiency}

Obviously, agriculture, by its nature is industrial - industrial process, if I'm going to be harsh and whatever. And digital agriculture is part of that way of running a more efficient, effective system that offers a lot of advantages to consumers. (Grower group 5).

So the ability to be able to have that real time data for me, or the ability to be able to remote access into a tractor and to have a look at the faults. So we're not travelling $200 \mathrm{~km}$ to go and do a job, that we're efficient. (Input provider 4)

\subsubsection{Norms: individualism; values and assumptions: economic values}

One of the risks of the big data collection is inevitably at some stage the cost is going to come back onto the producer to some degree and if they're accessing that data and they're getting it, those interactions between neighbours and some of that connectedness within neighbourhoods is going to be diminished to some degree. So you're going to get a little bit more isolation of individuals where when the pressure is on people are going to be - and we're already seeing it - are a little less inclined to come in to support each other because they've become more distant, particularly as farms get bigger and the aggregation goes on, that's another potential risk that would come into play... people's capacity to invest if they're not getting productivity, that's going to be a real challenge. (Local government 1 and 2)

\subsubsection{Values and assumptions: information is valuable}

That's what got us thinking about, well there's not really anything in it for the farmer to collect that data. But if that data is collected and utilised, A) it's going to be of huge value to the industry and B) its valuable. So we see it as potentially, maybe there's quite a few hurdles to go through, but it's potentially a reasonable funding source for BCG, as someone who is trusted by farmers to start something like that up and then with connections with the research community, work with farmers to make that information available to them the research community. Whilst at the same time, making a little bit of money for the farmer and a little bit of money for BCG. But probably, most of the value to the industry or the research community. (Grower group 6)

\subsubsection{Norm: revolution is an inevitable part of competition}

Step change is something that will be required in the Australian agricultural sector to remain internationally competitive. So looking at you know revolutionising the way we do things and not just finding those one, two percent gains around the fringes, which digital agriculture will help us with, but it could also help us make step changes in the way we farm and in the way we undertake business day to day. (Grower group 3)

\subsubsection{Rules: strive for maximum control}

What you're going to come up against is the companies who currently own and have spent literally billions of dollars putting that infrastructure in place where the grain is stored, they're not going to give up that information easily, and you can understand why. Why give it up to somebody who hasn't put the dollars in? (Logistics and trading 1) 


\subsection{Contra discourse: Big Data is for Everyone}

On the other hand, some believed that big data would be beneficial to everyone, that by improving things overall, everyone will be better off. Although, it was recognised that benefits to the farmer may take some time to flow back, until sufficient data is captured (and methods established for storage, analysis and reporting). It was also highlighted that it is difficult to get people to work together and that processes around leadership, in particular, are difficult for communal benefits. Key language: sharing; cooperation; working together. Rules: everyone needs to be involved for it to be successful. Norms: integrity; trust in others; if we all do our part we can all benefit; benefits will take time to accumulate. Values and assumptions: collective greater than the individual; farming is heterogeneous; helping the struggling.

\subsubsection{Key language: sharing}

So there's benefits to be achieved by sharing of information... So I think that's where big data could be quite useful in terms of collecting information on what sort of things have been achieved, of what sort of fertiliser applications, what sort of moisture, and our rainfall, things like that, what varieties are being sown and for what reasons, and capturing that sort of information is really, I feel, quite crucial to a progressive, robust and forward thinking industry. (Grower group 1)

More informed business decisions probably mean more stability and I also certainly see the ability for you know closer, better, more functional relationships along the supply chain. So growers having a more, I guess functional you know negotiated, integrated relationship with supply chain partners you know through the sharing, collation, information provision through big data and digital ag. (Grower group 3)

\subsubsection{Key language: together}

And if you all get together and market together, which you could if you had good information, then your product could suddenly be worth five times as much as it was if you didn't do that. (Local government 1 and 2)

I think there's value in the data that these companies are probably going to exploit and growers are not going to get an opportunity to see any value from it, and that's why I see, you know, in a cooperative stance, you know, compiling all of the data together is much stronger. (Grower group 7)

\subsubsection{Values and assumptions: helping the struggling}

So with more information I think it's going to make more marginal farmers able to manage well enough to stay sustainable, whereas without it that just wouldn't happen. (Local government 1 and 2)

\subsubsection{Norms: if we all do our part we can all benefit}

So I think that's one of the - that's the ironies or absolute conundrums around big data area that, for a start, the collection of data that an individual farmer, for example, would have available will only bring limited benefits, but over time and across industries as data gradually accumulates, then the benefits start flowing and flowing back to decisions on the farm. So it's quite an ironic or complicated issue because if you said to farmers, 'Start recording that data', I think a lot of the response would be, 'It's not much use to me', and it's not until you've got a body of that data accumulated that benefits start to flow and then they all flow back to the farmer. (Grower group 2)

There's a value proposition for them to, one I suppose, be involved in how they store their data and so they've probably got to get the individual proposition to start with, but also as a collective, because big data actually isn't - one farm's data isn't big data. (Grower group 5)

\subsubsection{Rules: everyone needs to be involved}

I don't think you'll ever get, like, equal participation from growers, but I think you'll find that all growers will participate in some way. (Grower group 1)

\subsection{Risk analysis}

The next stage of our discourse analysis looked at three key risks facing the industry that came out of the analysis: global competition, trust and infrastructure. Exploring how the two discourses frame these risks demonstrates key 'entry points' where dialogue, negotiation and cooperation may occur across the discourses, in order to address these issues 'in between' both discourses.

\subsubsection{Identified risk—keeping pace with the world}

One of the risks that can be identified for the future of big data in Australia is the need to keep up with international developments in big data, or risk getting external 'takeovers'. Australia has a unique context which is able to learn from 
systems deployed overseas, but these need to be adapted to the specifics of the Australian environment. Both the Big Data is for Big Farming and Big Data is for Everyone discourses see the need to adapt big data for Australian needs and contexts, and so, this is an opportunity to work across discourses.

We've owned these decision support tools for a while and been building up these systems and looking at acquisition of other, competitive products over the next few years and building on our platforms, but if we don't do that there will be international players that come into the Australian market, and Australian farmers will be at the whim of whatever the commercial incentive and the commercial imperative of those organisations is rather that what's in the grower's best interest... There is a risk that if we don't have the domestic capacity within Australia to keep pace with where our international competitors are that we'd get left behind. There is a risk that if we can't have the domestic capacity within Australia that where the vagaries of being taken advantage of by international markets and international competitors. (Grower group 3)

\subsubsection{Identified risk—need to build trust}

Another risk for big data in the future is the importance of trust. Within the Big Data is for Big Farming discourse, trust is more related to trust in data storage processes and in terms of what might be developed by government for the rules and restrictions of big data. For the Big Data is for Everyone discourse, trust was more about maintaining the rights for the individual farmer and ensuring benefits flowed back to the producers. Nevertheless, trust is an issue which both discourses are concerned about and which could therefore be harnessed to engage across discourses.

There's a whole heap of challenges that need to be placed around trust, around the way it's stored, accessibility, identification, because in the end - because I think most companies that would want to deal in this space don't actually care who the data is and actually don't want to know the individual. (Grower group 5)

The important thing about the platform being owned by an industry service's body and owned by the industry and owned by growers, is that the data remains the data of the growers as well. (Grower group 3)

\subsubsection{Identified risk—infrastructure limitations}

A third risk influencing the future of big data is the status of infrastructure currently around Australia-including access to the Internet in rural and remote regions as well as data handling capabilities and downloading speeds. Without these foundations, big data approaches are essentially impossible at the outset. As Australia is such a large country, equality of digital infrastructure is an issue that is exacerbated by developments in big data. Both discourses are concerned about infrastructure limitations because although big farms and corporations are more likely to have access to the necessary infrastructure, the regional location of many farms means that this is still an issue.

So having a telecommunication's infrastructure allows us to leverage the digital economy is absolutely critical. So a broadband based service through NBN [National Broadband Network], you know it would be a good start. How long and if there's sufficient capacity there is a bit of an unanswered question. Certainly our mobile telecommunication infrastructure is substandard across most of our growing grains region to fully leverage the digital economy. (Grower group 3)

\subsection{Impacts on industry}

The fact that the discourse of Big Data is for Big Farming exists demonstrates that for the benefits of big data to be equitably dispersed (i.e. for the Big Data is for Everyone discourse to be realised), there will need to be some concerted efforts into bringing the big side of industry on board, and by laying the foundations required for everyone who wants to participate to be able to participate. At a minimum, this involves improving access to Internet connections in parts of rural Australia, and by not excluding smaller farmers (through high start-up costs, complex contract arrangements, opaque data management or decision-making at higher levels). These concerns are no different to long-standing issues of benefits from agricultural intensification in developing nations, where resource-equipped farmers, often the rich and landed, gain more from technological innovations than those whom they may have been designed for - often resource-poor and vulnerable farmers. Alternatively, if the industry chooses that big data should be primarily for big farms, this can be a conscious decision with support and alternatives provided as required.

Issues of who engages with big data, how and to what effect, are complex and will require policy involvement. Some precedent has been set for big data guidelines in America, Europe and New Zealand (American Farm Bureau Federation 2017, Copa - Cogeca 2016, New Zealand Farm Data Code n.d.) which may act as useful guides for Australia. If equity is sought, it will be vital to maintain inclusivity of heterogeneous farmers in co-creating the rules for big data in their industry and in terms of transparency at all stages of data collection, storage and analysis. This is no easy task when 
each company is trying to achieve competitive advantage. Blockchain technology may offer some hope for keeping data secure and confidential but also keeping the iterations of data transparent (Godsiff 2016).

The discourse of Big Data is for Everyone highlights that an important part of sharing the benefits broadly and equitably is for everyone to get involved in some way. We know from the adoption literature discussed early in this paper that adoption of new technology and behaviour on farm is not necessarily an easy process, nor is it a 'one size fits all' scenario. So, there are definitely complexities in maximising participation. Nevertheless, this is still important to strive for, in order to prevent asymmetrical benefits later on. Farmer networks, farmer groups, advisory networks, co-creation of big data systems and sharing of knowledge and success stories are all important to encourage (Jakku et al. 2016).

\subsection{Implications for policy and practitioners}

The ethical, moral and practical questions posed in this paper about the beneficiaries, risks and value propositions inherent in big data require significant discussion between the policy community, technology providers, supply chain partners, farmers and their representative organisations. The discourses presented above signal the potential for dialogue amongst stakeholders to fracture into a binary debate, or false choice, between benefits of big data as concentrated amongst 'the few', or, as available to 'the many' farming enterprises in the grains sector. Instead, inclusive negotiation is required around the rules and norms both explicit and implicit in the emergence of big data and this active dialogue will enable the creation of discourse options to open up 'between' the binary positions we outline. Some priority areas of discussion could focus on the following concerns: firstly, the role that industry associations and research, development and extension (RD\&E) practitioners have in linking the wider industry to the conversation; secondly, the recognition that ethics of big data is an on-going conversation where safeguards around privacy and harm need to be put in place, without compromising the need to respond to how big data and its use can change over time; thirdly, how to link with policymakers around the globe - are the same discourses relevant? If there are contrasting discourses, what are the implications? Finally, does the digital age require a re-think of how design, development and use of data are informed by society's needs?

\section{Conclusion}

It's hard to say where we're going and how it will get there but, I'd absolutely see digital agriculture as one of the driving forces of change in industry over the next ten years. (Grower group 3)

Discourse analysis revealed two opposing views of how farmers and industry stakeholders perceive big data in the grains industry in Australia: Big Data is for Big Farming and Big Data is for Everyone. The result poses questions about the future of big data for agricultural industries worldwide. We have argued the need for industry, research providers and government to consciously, transparently and inclusively choose a path for the future of big data in agriculture and subsequently to make appropriate changes in policy and finance. There remains considerable scope for adjustment and the discourses will evolve as policies and technologies change, but now is the time for industry to consider what they want big data to achieve and to work together for this outcome or outcomes. Currently, problems exist in the distribution of benefits from big data and in (often unconscious) restrictions in access to, and in implementation of, big data approaches. Each of the two discourses has aspects which are desirable for a profitable future for Australian grain producers but they present quite different scenarios and require different policies, financial and social support. Avoiding informed and proactive dialogue about what kinds of futures are plausible and desirable for the development of big data in Australian agriculture could result in serious social and economic risks being left unmitigated and unmanaged. Factors such as intensity of production and resource utilisation, level of automation, value chains and wider community perceptions sit alongside big data, and the analysis provided here makes a start to better understand the values underlying farmer perceptions and their future positioning.

Acknowledgements The project team acknowledges the support and assistance of Michael Robertson and Dan Walker, and Chris Sounness, CEO Birchip Cropping Group, in the framing and implementation of the study. Many thanks to all of the participants who were interviewed and to the many CSIRO colleagues involved, especially Claire Mason.

Funding information This study was funded by CSIRO's Agriculture and Food Business Unit.

Open Access This article is distributed under the terms of the Creative Commons Attribution 4.0 International License (http://creativecommons. org/licenses/by/4.0/), which permits unrestricted use, distribution, and reproduction in any medium, provided you give appropriate credit to the original author(s) and the source, provide a link to the Creative Commons license, and indicate if changes were made.

\section{References}

Allen W, Cruz J, Warburton B (2017) How decision support systems can benefit from a theory of change approach. Environ Manage doi 59: 956-965. https://doi.org/10.1007/s00267-017-0839-y

American Farm Bureau Federation 2017 http://www.fb.org/ 
Bäckstrand K, Lövbrand E (2016) The road to Paris: contending climate governance discourses in the post-Copenhagen era. J Environ Policy Plan:1-19. https://doi.org/10.1080/1523908X.2016.1150777

Boyd D, Crawford K (2012) Critical questions for big data. Inform Commun Soc 15(5):662-679. https://doi.org/10.1080/1369118X. 2012.678878

Copa - Cogeca (2016) Main principles underpinning the collection, use and exchange of agricultural data, Online report, www.copa-cogeca. be/Download.ashx?ID=1566736\&fmt=pdf

Carberry PS, Hochman Z, McCown RL, Dalgliesh NP, Foale MA, Poulton PL, Hargreaves JNG, Hargreaves DMG, Cawthray S, Hillcoat N, Robertson MJ (2002) The FARMSCAPE approach to decision support: farmers', advisers', researchers' monitoring, simulation, communication and performance evaluation. Agric Syst 74: 141-177. https://doi.org/10.1016/S0308-521X(02)00025-2

Carbonell I (2016) The ethics of big data in agriculture. Internet. Pol Rev 5(1). https://doi.org/10.14763/2016.1.405

Carolan M (2016a) Agro-digital governance and life itself: food politics at the intersection of code and affect. Sociol Rural 57:816-835. https://doi.org/10.1111/soru.12153

Carolan M (2016b) Publicising food: big data, precision agriculture, and co-experimental techniques of addition. Sociol Ruralis 57:1-20. https://doi.org/10.1111/soru.12120

Carvalho A (2007) Ideological cultures and media discourses on scientific knowledge: re-reading news on climate change. Public Underst Sci 7:223-243. https://doi.org/10.1177/0963662506066775

Charmaz K (2006) Constructing grounded theory: a practical guide through qualitative analysis. Sage, London

Darier E (1999) Discourses of the environment. Blackwell, Oxford

Denzin N, Lincoln Y (2011) The SAGE Handbook of Qualitative Research. Sage

Dryzek J (2006) Deliberative global politics: discourse and democracy in a divided world. Polity, Canberra

Finan A (2007) Agriculture and ideology in a globalized world: a multiplicity of farmer discourses. $\mathrm{PhD}$ dissertation, Iowa state university

Fleming A, Vanclay F (2009) Using discourse analysis to better inform the practice of extension. Ext Farm Syst J 5(1):1-10

Fleming A, Vanclay F (2010) Farmer responses to climate change and sustainable agriculture: a review. Agron Sustain Dev 30:11-19. https://doi.org/10.1051/agro/2009028

Fleming A, Vanclay F, Hiller C, Wilson S (2014) Challenging dominant discourses of climate change. Clim Chang 127:407-418. https://doi. org/10.1007/s10584-014-1268-z

Foucault M (1980) Power and knowledge. The Harvester Press, Sussex

Glaser B, Strauss A (1967) Discovery of grounded theory: strategies for qualitative research. Aldine Publishing Company, Chicago

Godsiff P (2016) Blockchains could help restore trust in the food we choose to eat http://theconversation.com/blockchains-could-helprestore-trust-in-the-food-we-choose-to-eat-62276

Hajer M, Versteeg W (2005) A decade of discourse analysis of environmental politics: achievements, challenges, perspectives. J Environ Policy Plan 7(3):175-184. https://doi.org/10.1080/ 15239080500339646

Howden P, Vanclay F (2000) Mythologization of farming styles in Australian broad acre cropping. Rural Sociol 65(2):295-310. https://doi.org/10.1111/j.1549-0831.2000.tb00030.x

Huberty M (2015) Awaiting the second big data revolution: from digital noise to value creation. J Ind Compet Trade 15:35-34. https://doi. org/10.1007/s10842-014-0190-4
Jakku E, Thorburn PJ (2010) A conceptual framework for guiding the participatory development of agricultural decision support systems. Agric Syst 103(9):675-682. https://doi.org/10.1016/j.agsy.2010.08.007

Jakku E, Taylor B, Fleming A, Mason C, Thorburn P (2016) Big data, big trust and collaboration. CSIRO report: CSIRO online. https://doi. org/10.13140/RG.2.2.26854.22089

Johnston LM (2012) Discourses of security, agricultural innovation and nature: the Cuban transition to agro-ecology and the construction of campesino identity, Masters Dissertation, Carleton University, USA

Keogh M, Henry M (2016) The implications of digital agriculture and big data for Australian agriculture. Australian Farm Institute, Sydney

Kitchin R (2014) The data revolution: big data, open data, data infrastructures and their consequences. Sage, London

Kuehne G, Llewellyn R, Pannell D, Wilkinson R, Dolling P, Ouzman J, Ewing M (2017) Predicting farmer uptake of new agricultural practices: a tool for research, extension and policy. Agric Syst 156:115: 125-115:125. https://doi.org/10.1016/j.agsy.2017.06.007

Leeuwis C (2004) Communication for rural innovation: rethinking agricultural extension. Blackwell, London

Llewellyn RS, Ouzman J (2014) Adoption of precision agriculturerelated practices: status, opportunities and the role of farm advisers. In: CSIRO Report Published by GRDC, https://grdc.com.au/ Resources/Publications/2014/12/Adoption-ofprecision-agriculturerelated-practices

New Zealand Farm Data Code, n.d., http://www.farmdatacode.org.nz/

Pannell D, Marshall G, Barr N, Curtis A, Vanclay F, Wilkinson R (2006) Understanding and promoting adoption of conservation technologies by rural landholders. Aust J Exp Agric 46:1407-1424. https:// doi.org/10.1071/EA05037

Jorgensen M, Phillips L (2002) Discourse analysis: as theory and method. Sage, London

Poppe K, Wolfert S, Verdouw C, Renwick A (2015) A European perspective on the economics of big data. Farm Policy J. 12(1):11-19

Robertson M, Kirkegaard J, Rebetzke G, Llewellyn R, Wark T (2016) Prospects for yield improvement in the Australian grains industry: a review. Food Energy Sec 5(2):107-122. https://doi.org/10.1002/fes3.81

Sonka S (2015) Big data: from hype to agricultural tool. Farm Policy J 12 $1-9$

Stone P, Hochman Z (2004) If interactive decision support systems are the answer, have we been asking the right questions? In: New directions for a diverse planet. Proceedings of the 4th International Crop Science Congress, 26 Sep - 1 Oct 2004, Brisbane, Australia

Vanclay F (2004) Social principles for agricultural extension to assist in the promotion of natural resource management. Aust J Exp Agric 44:213-222. https://doi.org/10.1071/EA02139

Vanclay F, Enticott G (2011) The role and functioning of cultural scripts in farming and agriculture. Sociol Rural 51(3):256-271. https://doi. org/10.1111/j.1467-9523.2011.00537.x

Vanclay F, Mesiti L, Howden P (1998) Styles of farming and farming subcultures: appropriate concepts for Australian rural sociology? Rural Soc 8(2):85-107. https://doi.org/10.5172/rsj.8.2.85

Van Meensel J, Lauwers L, Kempen I, Dessein J, Van Huylenbroeck (2012) Effect of a participatory approach on the successful development of agricultural decision support systems: the case of Pigs 2 win. Decis Support Syst 54:164-172. https://doi.org/10.1016/j.dss.2012. 05.002

Wetherell M, Taylor S, Yates S (2001) Discourse as data: a guide for analysis. Sage, London

Wolfert S, Lan G, Verdouw C, Bogaardt MJ (2017) Big data in smart farming — a review. Agric Syst 153:69-80. https://doi.org/10.1016/j. agsy.2017.01.023 